H. ZHANG*, B. X. LI, B. WONG, A. STUMPF, C. G. SOWELL, F. GOSSELIN (GENENTECH, INC., SOUTH SAN FRANCISCO, USA)

Convergent Synthesis of PI3K Inhibitor GDC-0908 Featuring Palladium-Catalyzed Direct C-H Arylation toward Dihydrobenzothienooxepines

J. Org. Chem. 2019, 84, 4796-4802.

\title{
Category
}

Synthesis of Natural

Products and

Potential Drugs

\section{Synthesis of GDC-0908}

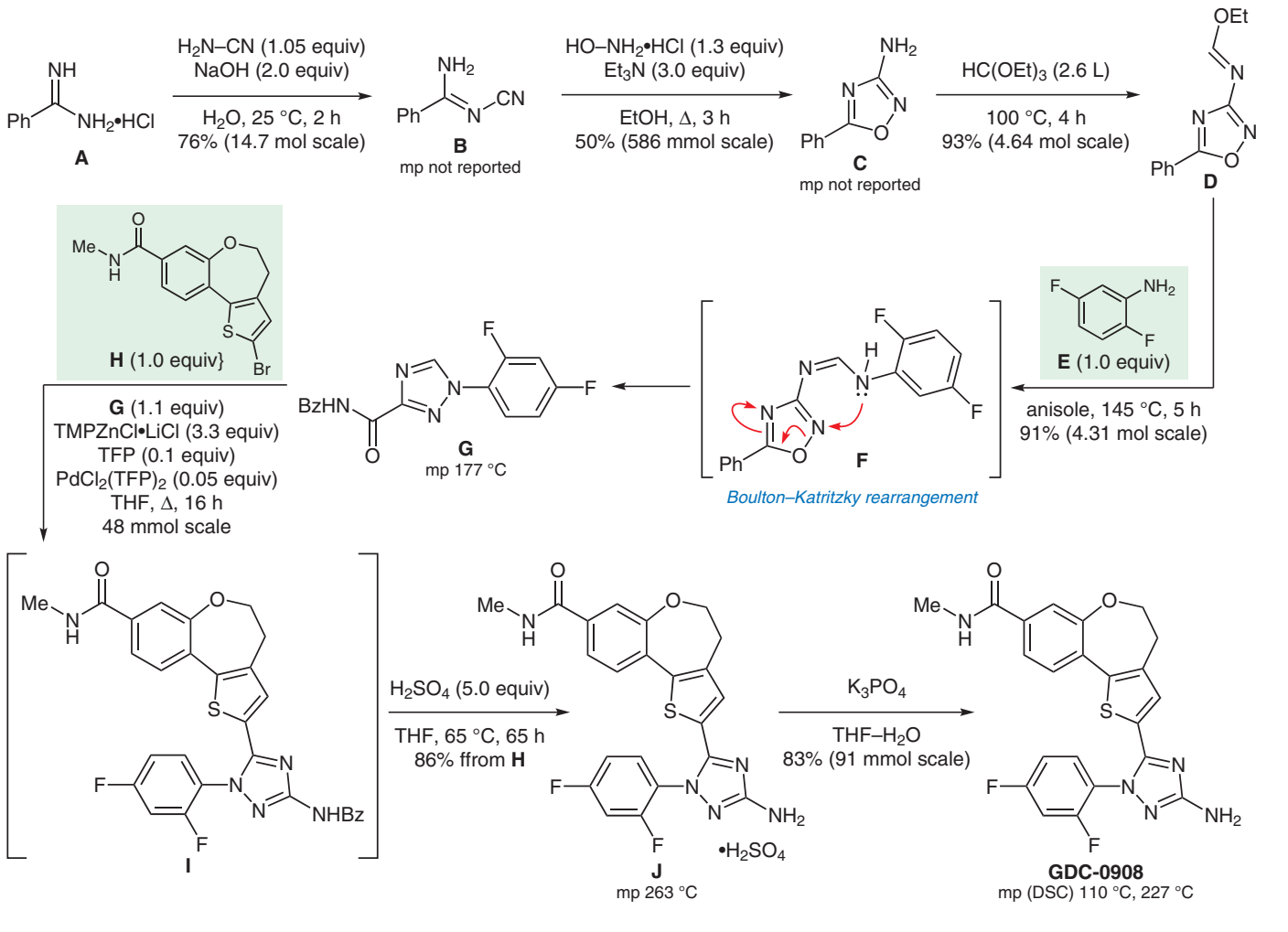

Synthesis of fragment $\mathrm{H}$ :

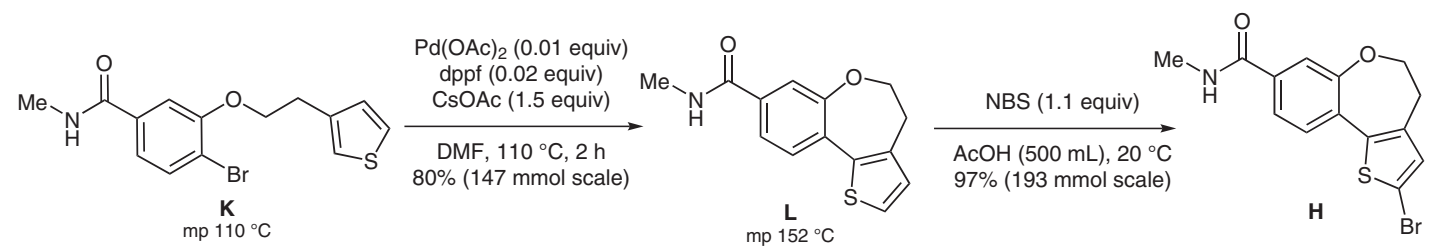

Significance: GDC-0908 is a phosphoinositide 3-kinase $\left(\mathrm{Pl}_{3} \mathrm{~K}\right)$ inhibitor that is of interest for the treatment of cancer. The convergent synthesis depicted features (1) a palladium-catalyzed direct $\mathrm{C}-\mathrm{H}$ arylation to construct 4,5-dihydrobenzo[b]thieno[2,3-d]oxepine L, (2) a Boulton-Katritzky rearrangement of 1,2,4-oxadiazole $\mathbf{F}$ to the 1,2,4-triazole G, and (3) a palladium-catalyzed Negishi reaction to forge the heterobiaryl linkage.
Comment: In order to deploy the Negishi coupling to forge heterobiaryl I, chemoselective metalation of the $\mathrm{C} 3-\mathrm{H}$ in triazole $\mathrm{G}$ was accomplished using the hindered Knochel base TMPZnCl $\bullet \mathrm{LiCl}$ (see Review below). An excess of the base (3.3 equiv) was required because of competing metallation of amide functionalities in $\mathbf{G}$ and $\mathbf{H}$.

Review: B. Haag, M. Mosrin, H. Ila, V. Malakhov, P. Knochel Angew. Chem. Int. Ed. 2011, 50, 9794-9824.
Key words

GDC-0908

phosphoinositide 3 kinase inhibitor

$\mathrm{C}-\mathrm{H}$ arylation

Negishi reaction

Boulton-Katritzky rearrangement

1,2,4-triazoles

1,2,4-oxadiazoles 